\title{
IDÉIAS
}

çào e avaliaçào de cargos, sistemas de avaliação de desempenho);

3) os sistemas de promoçào (ascensão e progressão funcionais) devem necessariamente levar em conta os programas de treinamento e especialização a que o funcionário se tenha submetido para o desempenho de funções do interesse do órgảo onde trabalha;

4) os programas de treinamento devem levar em consideração as atividades dos órgãos públicos e as respectivas funçōes atribuidas aos funcionários neles lotados, bem como os deveres destes perante o público e as instituiçōes;

$5)$ os cargos de chefia, com exceçōes criteriosamente estudadas, devem ser destinados a funcionários de carreira;

6) além do treinamento para o melhor desempenho de suas funções, o funcionário deve ser treinado para o eventual exercicio de funções mais complexas e de maior responsabilidade:

7) urge instalar o contencioso administrativo;

8) urge estimular o espirito classista do funcionário publico, dandolhe condiçōes de vocalizar os seus interesses mais legitimos e lutar institucionalmente por eles.

9) urge modificar o ordenamento juridico dos funcionários públicos civis, impondo à sua lei de criação um prazo de carência de no minimo cinco anos, durante o qual nem o Executivo nem o Legislativo modificariam qualquer um dos seus dispositivos; após esse prazo o ordenamento poderia sofrer as modificaçōes ditadas pela necessidade de seu progressivo ajustamento à realidade superveniente.

10) urge modificar a Constituição Federal, eliminando, do artigo 57 e incisos, a exclusividade de iniciativa do Presidente da Republica para leis que se refiram ao ordenamento juridico dos funcionários públicos - pois esta representa uma mordaça ao Poder Legislativo que inibe a sua legitima capacidade de representar e atender aos anseios dos mais diversos setores da sociedade brasileira e - por que não? dos funcionarios públicos civis!

\section{Mais produtividade pública é possível}

\section{Marianno Philgret(*)}

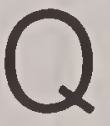

uando, com os mesmos recursos disponiveis, conseguimos aumentar o volume de produção, está configurada a elevação da produtividade. Esta, em sintese, é a relaçāo entre o que se produz e os insumos empregados.

Inúmeras formas são usadas para a determinação da produtividade, podendo-se lembrar, como exemplo, o relacionamento do número de toneladas de qualquer produto agricola obtido por hectare plantado.

Na iniciativa privada é comum aos empresários buscarem, valendo-se de métodos empiricos, elevar a produção pelo melhor emprego dos recursos de que dispōem. Mesmo sem aplicarem tecnologia mais avançada ou novas máquinas, conseguem reduzir os custos e/ou aumentar o nivel da produção, mantendo o numero de empregados, horas trabalhadas etc., ou seja, apenas aplicando outros processos produtivos, ou até pela motivação dos subordinados.

As empresas de porte, por disporem de recursos financeiros e maior conhecimento por parte de seus dirigentes, estabelecem condiçōes favoráveis para a busca permanente de mais alto nivel de produtividade. Grandes organizações mantêm departamentos que se dedicam unicamente à pesquisa no campo da racionalização do trabalho e adoção de tecnologia sofisticada. Não raro, utilizam testes psicológicos e cursos internos, mantendo altos padrôes de rendimento das equipes.

Pode-se dizer que na iniciativa privada e eficiència se confunde com a eficácia. A incessante procura de elevar a produtividade e aprimorar a qualidade dos produtos ou serviços e

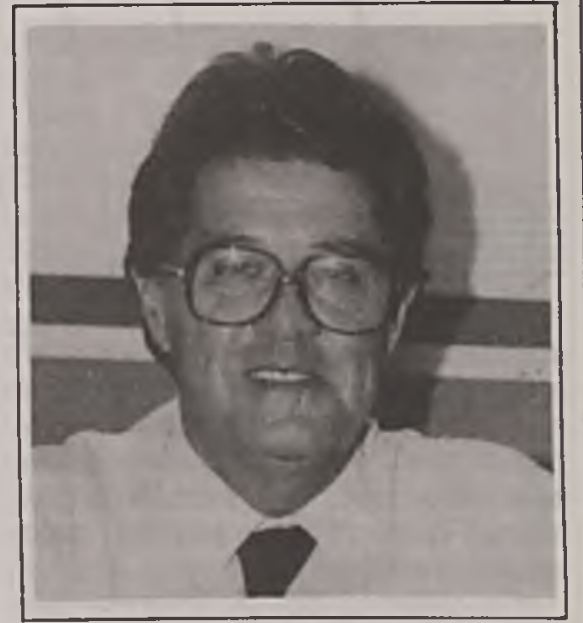

da mais alta importância na garantia do futuro da empresa. Ela é tida como eficiente devido ao adequado processo produtivo, e eficaz por bem atender às solicitaçōes do mercado.

No entanto, se nos voltarmos para a máquina administrativa governamental, encontramos distorções lamentaveis, tão bem enfatizadas em recente Exposição de Motivos dos Ministros do Grupo Executivo para a Reforma Administrativa (GERAP) ao Presidente da República. Os termos, às vezes acres, descrevem a situação caótica em que nos encontramos.

É pfovável que a diferença predominante entre o setor público e o privado esteja estreitamente ligada ao espirito empresarial. Salvo raras exceçōes, a grande maioria dos órgãos administrativos, nos três niveis do governo: federal, estadual e municipal, é dirigida sem a observância de principios básicos que devem reger as 


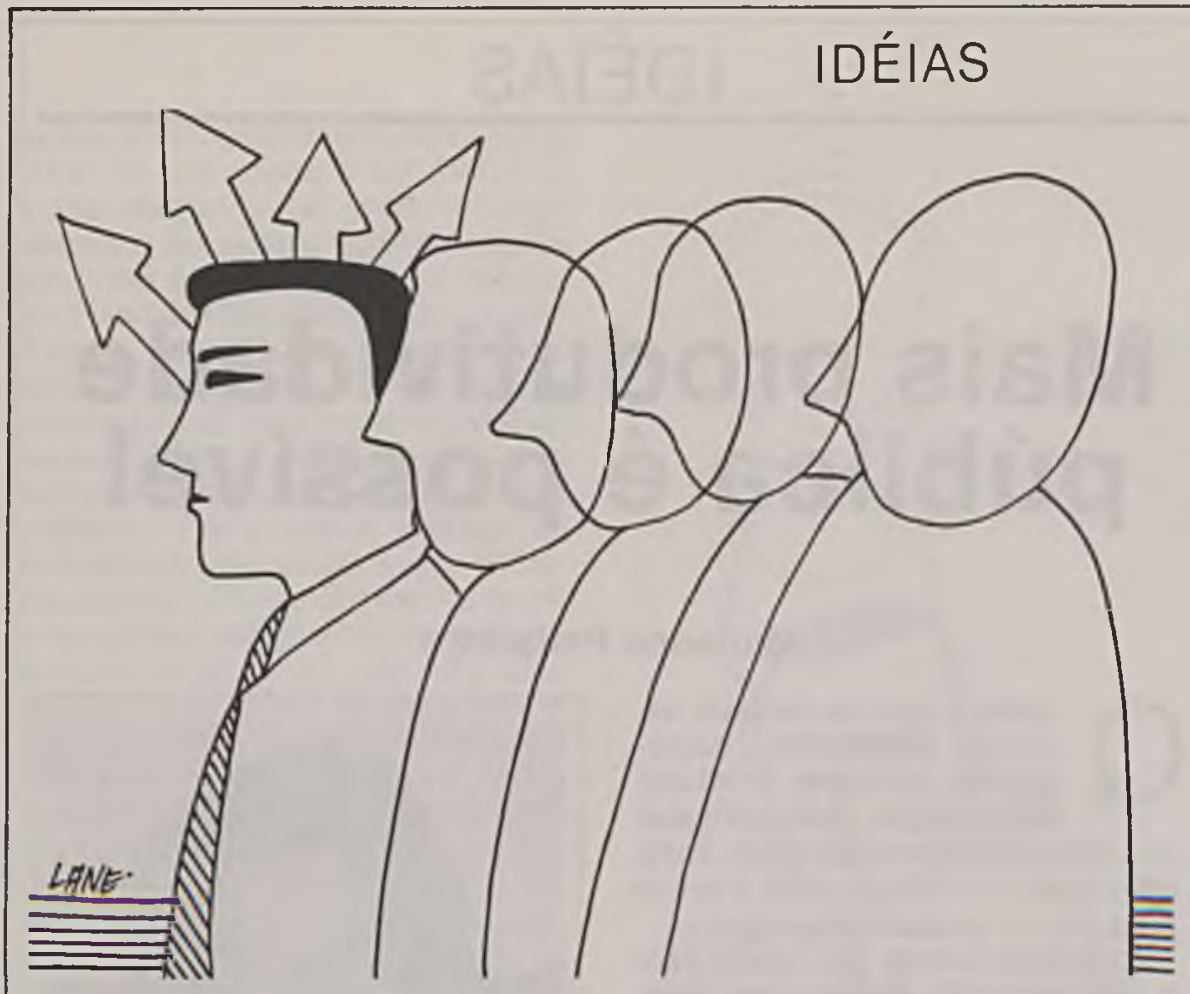

atividades, orientando-as para a consecução de seu fins. E comum aos serviços públicos deixarem de cumprir com eficácia o propósito de sua existência para se prenderem às rotinas burocráticas geradas pelo próprio sistema.

Os encarregados da reforma dão ènfase à necessidade de ser mudada a mentalidade predominante em quase todo corpo de funcionários. A reestruturaçāo terá de ser acompanhada da implantação dessa nova mentalidade, nos moldes empresariais. A mera reorganização da estrutura por certo poderia descomplicar, e talvez mesmo dar algum dinamismo ì enferrujada máquina, porem scus operadores nào estarào aptos a manobrála convenientemente se continuarem apegados a costumes arraigados, arcaicos. Por justiç, devemos lembrar que trabalham sem vislumbrar possibilidade de remuneração condigna e sem a certeza de acesso hierárquico. Aberto os horizontes e devidamente preparados para assumirem seus encargos, mudarão, em razoável pouco tempo, o comportamento ora dominante.

Não é justo imputar ao funcionalismo o estado em que se encontra a administração pública. Esta situação é conseqüência de erros e da displicencia das cúpulas administrativas anteriores.

É de toda conveniência, antes de procurarmos um processo que venha mente, e que uma grande parte ainda não se integrou à economia, carecendo de amparo e orientação, é evidente a necessária urgência da expansão dos serviços públicos, absorvendo, assim, a mão-de-obra liberada pela racionalização administrativa. Ressalta-se, ainda, imperiosa necessidade de ser observada criteriosa aplicação dos recursos orçamentários. Os desperdicios são por demais evidentes, e seria fastigioso enumerá-los. Não fazemos apologia da pura e simples contenção dos gastos públicos, mas sim da boa alocação dos recursos. E indispensável adotar a parcimônia gerencial, eliminando-se a irresponsabilidade impune. E imprescindivel ter por objetivo os fins, não os meios. Visase, enfim, que a administração pública se volte para fora, deixando de gerar e nutrir órgãos inócuos. $\mathrm{O}$ atendimento da comunidade e o respeito ao contribuinte devem ser constantes na atuação governamental. Frisamos: a razào de ser dos serviços públicos é atender à comunidade.

Instituída a austeridade no âmbito do Governo Federal, auxiliada por uma fiscalização mais intensa, seja por parte do Tribunal de Contas da União, e pelos demais órgãos de controle interno, seja por parte da própria sociedade, presenciaremos mudanças radicais no panorama presente.

Bem sabemos que o excesso de burocracia acarreta uma indesejável perturbação em todo sistema administrativo, mas devemos ter em mente não ser um mal restrito aos serviços públicos. Qualquer grande organização está sujeita ao gigantismo improdutivo, à proliferação de órgãos dispensáveis, aos excessos de regulação e aos controles supérfluos. No caso particular de nossa administração pública, chegamos ao limite. Como foi dito, torna-se imprescindivel reformularmos conceitos, em sua maioria profundamente arraigados, com raizes histórico-cultural.

O Governo Sarney vem gradativamente promovendo a reforma organizacional de inumeros setores, sem alarde já remanejou cerca de 10000 servidores para funçōes mais essenciais à população. Inaugurou e está ministrando novas formas de utilização dos recursos públicos, de combate às mordomias e ao desperdício no setor público. 